\title{
Política Económica y Política Social EN MÉXICO: DESEQUILIBRIO Y SALDOS
}

\author{
Felipe Torres y Agustín Rojas ${ }^{*}$
}

Fecha de recepción: 8 de diciembre de 2014. Fecha de aceptación: 9 de abril de 2015.

\begin{abstract}
RESUMEN
La adopción del modelo de economía abierta para reorientar la Política Económica en México provocó desequilibrios en el crecimiento y la distribución interna de la riqueza porque el control del entorno macroeconómico, rezaga los indicadores del bienestar social e incrementa la pobreza y desigualdad. Si bien la Política Social ha buscado compensar el deterioro en las condiciones de vida de la población, sus alcances son insuficientes en la medida que la misma Política Económica le impone límites que obligan a focalizar el gasto público hacia poblaciones objetivo con lo cual deja a una proporción amplia en situación de vulnerabilidad. Los datos muestran que la Política Social focalizada es incapaz de revertir los desequilibrios derivados por esta orientación de la Política Económica. No corregir los factores que rigen el modelo actual, vulnera gradualmente las condiciones de vida de la población y la seguridad nacional.
\end{abstract}

Palabras clave: Política Económica, Política Social, gasto social, pobreza, programas sociales.

Clasificación JEL: E61, I31, I32, I38.

\section{Economic and Social Policy in Mexico: Disparities ANd CONSEQUences}

\begin{abstract}
Mexico's adoption of an open-economy model to reorient its economic policy precipitated disparate growth and internal wealth distribution, as the control of the macroeconomic environment led to lagging social welfare indicators and increased poverty and inequality. Although Mexican social policy has sought to compensate for the deteriorating living conditions of its population, the scope of this policy is insufficient, insofar as the economic policy in place imposes limits that divert public spending towards certain target groups, leaving a broad swath of the people vulnerable. The data demonstrates that this targeted social policy has proved unable to reverse the disparities derived from the type of economic policy in effect. If we do not correct the factors that govern the current model, we risk gradually undermining the living conditions of the population and even national security.
\end{abstract}

Key Words: Economic Policy, Social Policy, social spending, poverty, social programs.

* Instituto de Investigaciones Económicas, unAM, México. Correos electrónicos: felipet@unam.mx y arojas2910@gmail.com, respectivamente. 


\section{POlitique ECONOMIQUe ET POLITIQUe SOCIALE AU MEXIQUE: DÉSÉQUILIBRE ET SOLDES \\ Résumé}

L'adoption du modèle d'économie ouverte pour réorienter la politique économique au Mexique a provoqué des déséquilibres dans la croissance et la distribution interne de la richesse du fait que le contrôle de l'environnement macroéconomique laisse en arrière les indicateurs de bienêtre social tandis qu'il augmente la pauvreté et l'inégalité. Si la politique sociale a cherché à compenser la dégradation des conditions de vie de la population, ses progrès sont insuffisants dans la mesure où la politique économique elle-même lui impose des limites qui obligent à destiner la dépense publique à des populations cibles sélectionnées laissant une forte proportion en situation de vulnérabilité. Les données montrent que la politique sociale sélective est incapable de renverser les déséquilibres découlant de cette orientation de la politique économique. $\mathrm{Ne}$ pas corriger les facteurs qui régissent le modèle actuel précarise progressivement les conditions de vie de la population et la sécurité nationale.

Mots clés: Politique Économique, Politique Sociale, dépense sociale, pauvreté, programmes sociaux.

\section{Política ECONÓMICA E POLÍTICA SOCIAL NO MÉXICO: DESEQUILÍbRIOS E SALDOS}

\section{Resumo}

A adoção do modelo de economia aberta para reorientar a Política Econômica no México provocou desequilíbrios no crescimento e na distribuição interna da riqueza, isso porque o controle do entorno macroeconômico penaliza os indicadores de bem-estar social e incrementa a pobreza e a desigualdade. Se bem é certo que a Política Social buscou compensar a deterioração nas condiçóes de vida da população, seus alcances são insuficientes, uma vez a Política Econômica lhe impóe limites que obrigam a focalizar o gasto público para populaçóes-objetivo deixando a uma ampla proporção em situação de vulnerabilidade. Os dados mostram que a Política Social focalizada é incapaz de reverter os desequilíbrios derivados por essa orientação da Política Econômica. Náo corrigir os fatores que regem o modelo atual torna gradualmente vulnerável as condiçóes de vida da população e a segurança nacional.

Palavras-chave: Política Económica, Política Social, gasto social, pobreza, programas sociais.

墨西哥经济政策和社会政策：失衡及后果

摘要：为重新调整经济政策，墨西哥采取了开放型经济模式。在这一模式下，对宏 观经济环境的控制降低了社会福利指标, 加剧了贫困和社会不公, 从而导致了经济 增长以及财富分配的失衡。尽管社会政策力图弥补居民生活条件的恶化, 但是其力 度是远远不够的。经济政策为社会政策强加了限制，使其不得不将公共支出用于目 标人群, 从而进一步扩大了弱势群体的范围。数据表明：有针对性的社会政策无法 扭转经济政策转向带来的失衡。如果不纠正当前经济模式的主导因素, 墨西哥居民 生活条件以及国家安全将逐步削弱。

关键词：经济政策，社会政策，社会支出，贫困，社会规划项目 


\section{INTRODUCCIÓN ${ }^{1}$}

A finales de los años setenta del siglo pasado, el modelo de desarrollo económico interno por sustitución de importaciones se agotó, o bien se reorientaron las estrategias que surtieron el mismo efecto. Esto provocó desequilibrios tales como la reversión de las tasas de crecimiento positivas logradas durante el llamado "milagro económico de México". A principios de los años ochenta, el país enfrentó una crisis de endeudamiento y débiles resultados de crecimiento generados por un nuevo modelo de desarrollo económico que, sustentado en la apertura comercial y desregulación, buscaba reestructurar las fallas aducidas a la participación del Estado en la economía, combinada con gastos sociales excesivos.

La crisis económica interna impulsó la aplicación de políticas económicas de estabilización y ajuste estructural basadas en pactos. Las políticas monetarias y fiscales buscaban contener los altos niveles de inflación, restaurar el equilibrio en la balanza comercial y reducir el déficit público. Sin embargo, sus resultados reflejaron una mayor desestabilización de la economía, la incapacidad del Estado para impulsar el desarrollo económico y el traslado del costo del ajuste estructural a las familias; ello intensificó las desigualdades sociales y regionales expresadas en mayor pobreza y marginación.

A partir de los años noventa, la Política Económica subordinó las necesidades del país a las estrategias que sigue la dinámica económica mundial, lo que debilita el crecimiento interno y no detiene los impactos que el modelo de economía abierta genera en la población; esto incrementa la tensión y el descontento social. Así, la Política Social es rebasada para actuar como mecanismo de contrapeso, ya que impone restricciones al ejercicio del gasto social que obligan a focalizar los recursos públicos, reorientar programas de atención y reducir coberturas de población y territorio. En síntesis: la Política Social en México se encuentra marginada por los intereses de la Política Económica cuyas estrategias se encaminan al fortalecimiento de la concentración y no de una distribución más equitativa de la riqueza.

El tránsito hacia un proyecto de desarrollo e inversión pública, que atienda las necesidades internas con una nueva Política Social renovada que amplíe su cobertura y magnitud, será vital para lograr el crecimiento económico mediante una redistribución adecuada del ingreso y, así, alcanzar la equidad social.

Este trabajo es resultado del proyecto PAPIIT IN300815 “Dimensiones regionales de la seguridad alimentaria en México". 


\section{POLÍTICA ECONÓMICA Y POLÍTICA SOCIAL EN EL MARCO DE ECONOMÍAS ABIERTAS}

La economía mundial ha enfrentado cambios permanentes en los últimos 40 ańos. El progreso tecnológico en comunicaciones y transportes redujo distancias y costos de producción, lo que modificó las formas tradicionales de organización laboral, la circulación y el consumo de bienes y servicios. También transformó la organización social con respecto a otras precedentes que garantizaban mejores equilibrios a través de la Política Social y se suscitaron modificaciones en las funciones del Estado Nacional en cuanto a la conducción de la Política Económica.

Esta última, representa el conjunto de normas y lineamientos con que el Estado regula y orienta la dinámica económica del país, además de establecer criterios que, acorde al Plan Nacional de Desarrollo, engloban el comportamiento de diversos ámbitos de la vida nacional y los instrumentos correspondientes para su operación a través de políticas como la fiscal, monetaria y exterior. De aquí se desprende la Política Social y diversas políticas sectoriales y regionales. La Política Social constituye el medio con el cual el Estado procura redistribuir la riqueza, preservar el bienestar social y que los beneficios derivados del desarrollo económico alcancen a todos los estratos sociales.

La Política Económica y la Política Social son regularmente procesos separados dentro del Estado. La primera interviene sobre la dimensión económica, la segunda sobre la social en cumplimiento de leyes que se expresan en la aplicación de programas sociales.

Como lo constata la historia económica reciente, el modelo de desarrollo económico imperante concede primacía a la Política Económica orientada al crecimiento y propone mecanismos distributivos a través de la Política Social. Esta última buscaba el fomento del bienestar, pero ahora es la herramienta del Estado para corregir ex post las desigualdades. Así, primero se determinan los alcances de la Política Económica y, posteriormente, se emplea a la Política Social para paliar sus efectos negativos.

La institucionalización de la Política Social como herramienta de la Política Económica constituye un fenómeno reciente. En el Estado antiguo (la polis griega y el Imperio romano), se estimulaban lazos de solidaridad entre familias y comunidades; en el Estado moderno, que enfrentó fenómenos como la peste negra, las hambrunas del siglo XIV o la legalización de la asistencia a necesitados con la Ley de Pobres de 1601, buscaba paliar las revueltas sociales generadas por las condiciones infrahumanas de subsistencia (Thompson, 2002: 19-42). Con ello el Estado Benefactor formaliza a la Política Social 
como Política de Estado (Flinn, 1970: 8-9; 17-19; Hobsbawm, 1983: 15-29; Rheinheimer, 2009; Villarespe, 2002: 15).

Desde los años cuarenta y hasta finales de los setenta del siglo pasado, las estrategias de crecimiento económico de diversos países en desarrollo se basaron en la intervención del Estado en la actividad económica bajo un modelo industrial por sustitución de importaciones y de fortalecimiento del mercado interno (Pérez, 1996: 347-363). Diversas naciones experimentaron avances reflejados en altas tasas de crecimiento del Producto Interno Bruto (PIB) que, como en el caso de México, superaron el 5\% anual.

Ese modelo transformó al sistema de producción: abandonó el modelo agrario-exportador y colocó a la industria como el motor de crecimiento económico y de fortalecimiento del mercado interno. La estrategia minimizó primero a las actividades de bienes de consumo no duraderos y transitó hacia aquellas con mayor grado de complejidad como los bienes intermedios y de capital. Asimismo, alteró la estructura socio-espacial de las inversiones e incrementó el número de trabajadores asalariados que migraron del campo hacia los centros urbanos e industriales (Guillén Romo, 2001: 20-21). El Estado participó activamente en la economía, principalmente en la protección y fomento a las empresas nacionales, la fijación de aranceles, precios de garantía, apoyos fiscales y exenciones; además, creó instituciones especializadas para atender diversas problemáticas sectoriales.

En este contexto se edifica el Estado Benefactor que impulsó el desarrollo económico y el bienestar en alimentación, salud, vivienda y educación (Montagut, 2008: 53-75). Para ello, desplegó una Política Económica de corte nacionalista orientada al crecimiento de la capacidad productiva, el estímulo de la demanda agregada con políticas fiscales y monetarias de corte expansivo y el incremento del empleo e ingreso. Con la provisión de servicios básicos baratos, garantizó también la seguridad social y atenuó los desequilibrios internos que afectaban a algunas regiones. El gasto público creciente posibilitó la redistribución de recursos y el bienestar social.

Si bien el Estado Benefactor intentó brindar cobertura universal en derechos básicos, a nivel internacional se presentaron tres distintos regímenes de bienestar y de protección social que sincronizaron de manera distinta a la Política Económica y la Política Social. El primero de ellos, el socialdemócrata, procuró garantizar a toda la población, de forma institucionalizada, la provisión de un conjunto de satisfactores, ya que al asegurar los niveles mínimos de bienestar suponía avanzar hacia un modelo de desmercantilización de los servicios sociales y el acceso más allá de las restricciones que impone el mercado. El segundo, el conservador, en contraste con el anterior, estratificó y 
normativizó el acceso a bienes y servicios, diferenciando su provisión por tipo de ocupación, al otorgar privilegios a los trabajadores industriales a través del seguro social. Finalmente, el liberal, sólo intervenía si comprobaba que los individuos no contaban con recursos suficientes para acceder a bienes y servicios básicos (Esping-Andersen, 1999).

Esta sincronía entre Política Económica y Política Social ha sido modificada en el marco de desarrollo económico actual. La nueva ideología de libre mercado gestó una separación de la forma en que ambas políticas operaron durante el periodo de Bienestar y permitían el equilibrio relativo entre desarrollo económico y aspiraciones sociales. El replanteamiento de esta relación refleja el tránsito hacia el modelo de economía abierta impuesto por la dinámica económica de orden global (Chossudovsky, 2003: 319-326; Guillén Romo, 1997; Vidal Villa, 1998: 105). Por tanto, partimos aquí de la hipótesis que los lineamientos establecidos por la Política Económica interna vinculada a los mercados abiertos, la cual contiene como estrategia el control de las variables macroeconómicas, impactan gradualmente en la disminución del gasto social y así la Política Social resulta incapaz de garantizar equilibrios en el desarrollo de México.

Entre 1980 y 1982, la caída de los precios internacionales del petróleo y el incremento en las tasas de interés en el mercado internacional de capitales, complicaron el entorno macroeconómico en diversas naciones, provocando desequilibrios internos y externos, principalmente en el presupuesto público, nivel de empleo, inflación y en el déficit de la balanza comercial y de pagos. Además, en la imposibilidad de sostener los niveles de crecimiento económico, ya que la industrialización sustitutiva no integró una red industrial y tecnológica efectiva, lo que generó bajos niveles de productividad nacional e interregional y rezago de las exportaciones.

La estrategia de industrialización del modelo sustitutivo implicó un sesgo intersectorial. En el caso de México, el rezago de la estructura agropecuaria disminuyó la producción de materias primas y productos básicos y la pérdida de la autosuficiencia alimentaria, agudizando los desequilibrios en la Balanza Comercial Agropecuaria (Guillén Romo, 2001: 24-25; Torres, 2003: 15-52). Aunado a ello, los choques macroeconómicos externos significaron un freno al crecimiento económico y a la continuidad de la sustitución de importaciones. El déficit de las finanzas públicas obligó a recurrir al financiamiento externo, lo que puso en cuestionamiento la efectividad de la Política Económica del Estado.

El aumento del gasto público como corrector de los desequilibrios en lo económico y en lo social provino de préstamos otorgados por organismos 
financieros supranacionales. La agudización de los desequilibrios financieros provocó que las naciones deudoras como México cubrieran sus pagos con intereses más elevados, inhibiendo el crecimiento interno. Ante el incremento del servicio de deuda, algunas se declararon insolventes (Damián, 2002: 27). Las condiciones estructurales de la crisis en que se encontraban economías como la nuestra impidieron saldar compromisos y desataron un nuevo ciclo de endeudamientos, aunque bajo condiciones de ajuste casi permanente (Girón, 1991).

La implementación de la agenda de estabilización y ajuste estructural buscaba recuperar los niveles de producción y consumo previamente alcanzados, pero bajo una perspectiva del desarrollo regida por la libertad de los mercados; misma que sustenta que las causas que inhiben el crecimiento económico, tienen como causal a políticas de corte nacionalista y la excesiva intervención del Estado, pero además legitimada con gastos sociales improductivos y no en factores que propician el crecimiento y la concentración de capital (Cruz y Polanco, 2014: 9-33).

Bajo este enfoque, los organismos financieros internacionales acreedores diseñaron programas de ajuste para estas economías inestables y de pobre desempeńo, a fin de asegurar el pago de la deuda, aunque trasgrediendo y subordinando su soberanía nacional (Girón, 2004: 189-208; 2006: 125-142). Consecuentemente, la cautela fiscal, la desregulación y la liberalización financiera y comercial, orientaron el rumbo de la Política Económica, además de que ajustaron los planes de desarrollo a las directrices de la economía mundial. La Política Social se limitó a contener los efectos adversos generados por la dinámica económica de orden global (Franco, 1985: 13-20; Sotelo, 2010).

En el periodo de economía abierta, el mayor costo para el bienestar deviene del cambio en la conducción de la Política Económica por las limitaciones del Estado para contrarrestar las distorsiones económicas y las desigualdades a través de la Política Social. A partir del ajuste, la Política Económica impuso límites estructurales a la Política Social, confinando su atención a la población en condiciones de pobreza, sin posibilidades de cubrir aspectos básicos del bienestar y con acceso precario al consumo alimentario (Arellano, 1985: 41-45; Boltvinik, 2005: 131-196; Campos, 2010: 51; Townsend, 2003: 445449; Uribe, 2011: 37).

Si bien durante la fase proteccionista la Política Económica redistribuía recursos mediante la Política Social y logró avances significativos en materia de seguridad social porque convertía al Estado en regulador del mercado y la distribución del bienestar, en el contexto actual racionaliza los recursos públicos, abandona la supervisión y control sobre lo social, así como la promoción del 
desarrollo nacional (Barba, 2004: 17-24; Gordon, 2009). La Política Social actual se rige bajo parámetros de focalización de apoyos para la asistencia y abatimiento de la pobreza, con el objeto de hacer más eficiente el gasto público. Esto elimina acciones que universalizaron el beneficio de amplios sectores; además privatiza, desregula y descentraliza las acciones que debe detentar el Estado (Campos, 2010: 51-52).

Asimismo, implementa mecanismos de combate a la desigualdad en el marco que impone la Política Económica de libre mercado a un Estado reducido y con bajos márgenes de control social, asumiendo que la eficiencia del mercado genera bienestar económico y social. El supuesto es que permite a los excluidos integrarse al circuito económico y disfrutar de los beneficios derivados; por tanto, se orienta a la cobertura de población residual del mercado. Se sacrifica el gasto social para canalizarlo a actividades que permitan fomentar el crecimiento económico impulsado por agentes privados.

La aplicación de esos lineamientos provoca que la focalización no sólo modifique la forma de utilización de recursos, sino también, el tamaño de la población objetivo de programas sociales, reduciendo el monto de recursos y la cantidad de beneficiarios, y que los agentes económicos privados sean ahora oferentes y cubran demandas sociales anteriormente proporcionados por el Estado, inclusive en áreas estratégicas. Se ha desarrollado un esquema basado en la eficiencia y maximización de recursos, mediante la evaluación de los programas implementados, a fin de seleccionar los más eficientes y reestructurar -o eliminar-aquellos que están debajo de los parámetros mínimos fijados, sin cambiar las condiciones de desigualdad (Cardozo, 2005: 172).

El tránsito de un Estado Benefactor a un Estado mínimo ha implicado la racionalización de recursos públicos y el abandono de la dimensión social. En el caso de México, la Política Económica actual provoca efectos adversos en la economía nacional que rebasan los alcances del Estado para generar una agenda de desarrollo acorde a las necesidades internas del país. Desde la apertura comercial, las bajas tasas de crecimiento económico reducen la posibilidad de que la focalización impacte favorablemente a la población más vulnerable.

Si bien el país logró beneficios sociales durante el Estado Benefactor, los rezagos acumulados y las crisis económicas desde la transición hacia el modelo económico de libre mercado en un contexto de problemas estructurales no resueltos, reducen la Política Social a un mero mecanismo de contención de pobres sin eficacia, ya que los desequilibrios internos generados por la Política Económica superan la cobertura de la Política Social, que no encuentra compensaciones ante el deterioro progresivo del ingreso individual. 


\section{POLÍTICA ECONÓMICA Y POLÍTICA SOCIAL EN MÉXICO. SITUACIÓN ACTUAL}

La transición de la economía mexicana hacia el modelo de economía abierta está cruzada por un proceso de estabilización de las variables macroeconómicas inspiradas en la llamada Política Económica de ajuste estructural. Desde su instauración se han presentado bajos niveles de crecimiento y una frágil estabilidad económica. Al igual que otras naciones en desarrollo, la estabilización, que tiene como prioridad el control inflacionario y del déficit externo, no genera las dinámicas de crecimiento requeridas por la economía interna; su lentitud se traduce en un alto costo social, pero además, en la persistencia de crecientes déficits en las finanzas públicas, aumentos del desempleo abierto y crisis macroeconómicas recurrentes que amplían la brecha de desigualdad social.

La evidencia empírica muestra que a partir de la apertura comercial se han suscitado desequilibrios internos, tanto en sus vertientes sociales, como territoriales, reflejados en una mayor concentración de la riqueza, incremento en los niveles de pobreza y desigualdad, pero además, en nuevas problemáticas de orden multidimensional a escala individual y social (Boltvinik, 2005), que han rebasado la dimensión económica: el crimen organizado, el narcotráfico, la exclusión social, o bien, la violencia estructural generalizada que azota actualmente al pais, entre otros factores, son claro ejemplo de ello.

La conjunción de resultados económicos y sociales negativos desencadenó las tensiones sociales actuales y los riesgos sobre la propia seguridad nacional. En esa dimensión se expresan los límites estructurales a la Política Social. De esa forma, los rezagos sociales del país, los desequilibrios internos, así como la parálisis del ritmo de crecimiento económico, están asociados por un lado, a la reorientación de la Política Económica, convergente ahora con el modelo de economía abierta, y por otro, con la imposibilidad de la Política Social para responder a los desequilibrios generados por la forma de conducción de la propia Política Económica.

Aunque la Política Social es el vector que busca atenuar los conflictos propiciados por la desigualad social mediante el ejercicio del gasto público, éste ya no representa una prioridad real en la agenda nacional porque la efectividad de la Política Social está condicionada por el éxito de la Política Económica. Si bien la Política Social instaurada en México tiene rasgos específicos respecto de otros países, comparte otros propios del modelo de economía abierta. Sus objetivos y alcances se han delineado no sólo en función de parámetros y necesidades internas, sino también como consecuencia de pautas que impone el 
desarrollo internacional. El que diversas naciones hayan experimentado procesos afines en el deterioro de sus condiciones de vida a partir de las últimas tres décadas del siglo xx, demuestra que la Política Social comparte rasgos dados por la especificidad de la Política Económica de cada país.

En México, la Política Social muestra tres etapas claramente definidas (véase cuadro 1): cada una se encuentra orientada por las políticas económicas dominantes en curso. La primera corresponde al periodo posrevolucionario; la segunda al experimentado a partir de la década de los cuarenta y hasta los setenta; la tercera inicia en los ochenta, con la denominada Reforma Política del Estado, resultado del cambio de modelo económico impuesto por el proceso de economía abierta y de la reorientación de la Política Económica interna derivado del ajuste estructural (Cardozo, 2005: 170-173; Jusidman, 2009: 200).

El origen de la Política Social mexicana se encuentra marcada desde el periodo posrevolucionario, con la orientación de contenidos de la Constitución Política de 1917, desde lo cual intenta corresponder a las demandas sociales de la Revolución mexicana. El Estado reconoce los derechos sociales e instaura medidas para revertir las desigualdades y rezagos sociales que aquejaban al país, principalmente en el campo, y ser garante de derechos.

En esta etapa la Política Social no fue integral, como en el caso de la experiencia europea, ya que se buscaba hacer valer los derechos constitucionales más allá de su cobertura universal. Sin embargo, debido a que integró derechos sociales básicos, representa un avance en justicia social y es una pieza clave para la conformación de un proyecto de desarrollo industrial nacional (Cardozo, 2005: 171; Gordon, 2001: 26-29).

La segunda fase aparece con la consolidación del modelo de industrialización por sustitución de importaciones, a partir de los ańos cuarenta y hasta finales de los años setenta del siglo xx. Si bien en la etapa previa buscó asegurar la provisión de los derechos sociales básicos, esta nueva fase se orientó a fortalecer la industrialización y el desarrollo tecnológico nacional (Uribe, 2011: 47-52). El impulso a un proyecto estratégico-nacional de crecimiento exigió la creación de instituciones que garantizaran el funcionamiento de redes corporativas y la distribución de los beneficios, pero que además operaran otros instrumentos de redistribución. En esencia, se buscaba brindar un marco institucional-redistributivo.

Esta etapa coincide con la Segunda Guerra Mundial, la cual generó un incrementó en la demanda de bienes de exportación, básicamente hacia el mercado norteamericano. Este incremento permitió al Estado mexicano generar un plan de inversión orientado a crear la infraestructura básica que exigía el proyecto de industrialización y desarrollo del mercado interno estimulado 


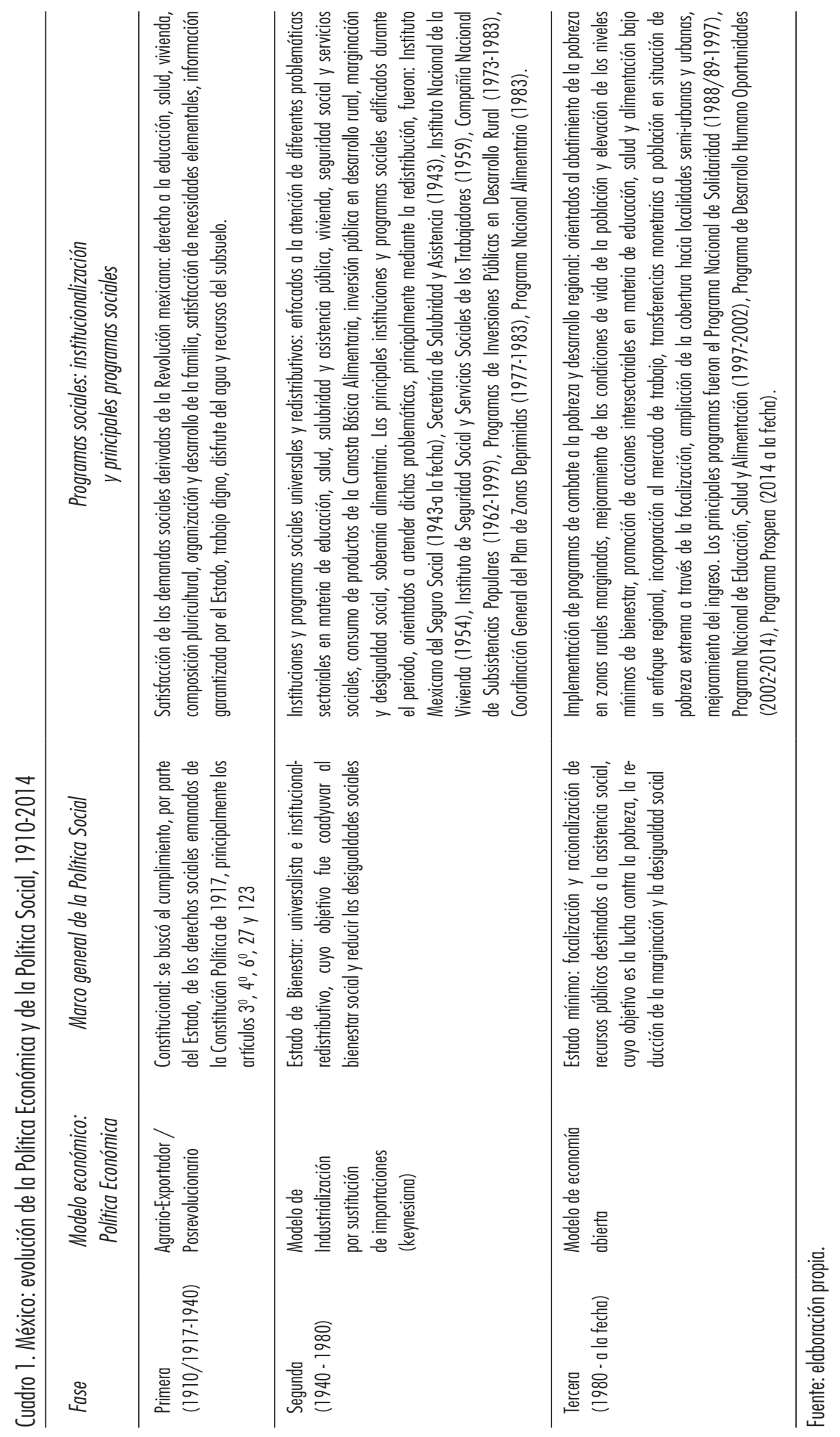


por los mayores ingresos fiscales procedentes del comercio. La bonanza logró afianzar el marco institucional para brindar los servicios sociales básicos a la población.

Debido a su connotación industrial concentrada, el proceso de crecimiento provocó desigualdades sectoriales, principalmente en el sector agrícola, que si bien lograba generar excedentes para afianzar el desarrollo, posteriormente entró en rezago y crisis. Ello generó un éxodo masivo de campesinos hacia los centros urbanos, provocando grandes contrastes en el crecimiento de las ciudades. La década de los cincuenta obligó a una reorientación de la Política Económica y Social, para responder ahora a la problemática generada por el llamado "proceso de urbanización salvaje", básicamente en los casos de la Ciudad de México, Monterrey y Guadalajara.

La transición de un patrón de asentamiento predominante rural hacia otro urbano generó cambios significativos en los estilos de vida, en las estructuras familiares y el consumo de los hogares, que desembocaron en una transformación de las necesidades sociales y en la alteración de los parámetros mínimos de bienestar. El Estado estableció lineamientos para atender las necesidades mediante la racionalización del gasto social.

Los desequilibrios sectoriales propiciaron el agotamiento del modelo de industrialización. La excesiva protección del Estado, que desembocó en menores niveles de competitividad de las empresas nacionales, y la inequitativa distribución regional de los ingresos, que empezaba ya a generar descontento social, fueron algunos de los factores que frenaron la dinámica económica precedente y la irradiación de beneficios sociales.

El deterioro sistemático del nivel de vida de la población a partir de los años setenta, resultado del bajo ritmo de crecimiento y la agudización de las desigualdades sociales, reorientó nuevamente la Política Social. Ante la inestabilidad experimentada en el país, el Estado implementó los Programas de Inversiones Públicas en Desarrollo Rural (PRIDER) en 1973, y más tarde la Coordinación General del Plan Nacional de Zonas Deprimidas (Coplamar), a fin de resarcir los rezagos sociales en las zonas rurales. De igual manera, la apertura del Sistema de Tiendas Rurales así como el Sistema Alimentario Mexicano (sAm) en 1980, lo cual mostraba la clara preocupación por el aumento de la pobreza en las zonas rurales (Barba, 2004: 27-31; Boltvinik y Marín, 2003: 473-475).

Para contrarrestar los efectos de la deuda de los años ochenta se implementaron programas de ajuste estructural, provocando un cambio radical en la Política Económica y consecuentemente en la Social. Esto posibilitó la Reforma del Estado, lo cual inicia la tercera etapa de las políticas sociales 
en México, caracterizadas por ser más selectivas y diferenciadas al focalizar y racionalizar los recursos públicos, pero sobre todo, por la atención social de tipo individualizado ante la hegemonía del modelo de economía abierta. En ese sentido, el conjunto de programas sociales gestados desde la primera mitad de la década de los setenta y que integraban primordialmente al PRIDER y a la Coplamar, fueron reorientados y convertidos en Programas de Desarrollo Regional (Barba, 2004: 29-31).

A principios de los años noventa, la Política Económica de orden global delimitó los alcances de la Política Social en México, y transformó tanto el contenido como el sentido social de los programas. Prueba de ello es el Programa Nacional de Solidaridad (Pronasol), que surgió a finales de los años ochenta y en su tránsito a los años noventa se orientó a una población definida como pobres extremos. Este programa buscó atender las necesidades más apremiantes en materia de alimentación, vivienda, educación y salud de la población integrada por los pobres urbanos, campesinos de escasos recursos y grupos indígenas. También intentó realizar proyectos de colaboración con los beneficiarios del programa, estableciendo mecanismos de obligación y responsabilidad compartida. A través de ello el gobierno federal aportó recursos técnicos y financieros y los beneficiados algunos tipos de trabajo como faenas comunitarias. Otro de los objetivos planteados fue el de mejorar la infraestructura agropecuaria rezagada.

En 1997 se gestó el Programa de Educación, Salud y Alimentación (Progresa), el cual combinó apoyos en educación, salud y alimentación, a fin de formar capital humano en comunidades y familias pobres. El objetivo era romper círculos intergeneracionales de pobreza extrema, asociados con elevados niveles de desnutrición, mortalidad infantil, deserción escolar y bajas posibilidades de acceso a la salud. En la práctica no representó una opción más allá de un programa de transferencias focalizadas; de igual manera estuvo sujeto a evaluaciones periódicas a través de encuestas aplicadas a sus beneficiarios.

Al inicio del presente siglo y hasta mediados de 2014, la Política Social se rigió por el Programa Oportunidades que representó una extensión de Pronasol. El rasgo distintivo fue la ampliación del rango de cobertura a localidades urbanas, y además, a la población en extrema pobreza que padece los más altos índices de desnutrición, marginación y rezago social. En ese sentido, buscó incrementar las capacidades de sus integrantes y ampliar posibilidades de mejores niveles de bienestar mediante su escolarización, salud y nutrición.

Más recientemente se instauró el Programa Prospera, principal estrategia del gobierno federal actual para el combate a la pobreza. Aunque se mantiene el mismo esquema de beneficios para aquellos que se encontraban inscritos en 
Oportunidades, el reciente programa adiciona apoyos en cuanto a becas universitarias, créditos y acceso a programas emprendedores, además de raciones alimentarias directas mediante la Cruzada contra el Hambre.

Si bien se han implementado en México programas orientados a combatir la pobreza y reducir las desigualdades, los indicadores que miden el bienestar muestran un deterioro sistemático y el fracaso, visto por el incremento sin precedentes de la pobreza, de los programas sociales surgidos del proceso de economía abierta, donde la Política Social deja de cumplir su función histórica como mecanismo de contrapeso ante las adversidades del desarrollo económico.

\section{LA VULNERABILIDAD DE LOS INDICADORES EN MÉXICO BAJO EL MODELO DE ECONOMÍA ABIERTA: SALDOS DEL DESEQUILIBRIO}

Si bien la medición de los indicadores económico-sociales permite la generación de información y toma de decisiones, la debacle de éstos desde hace 30 años no representan todavía para el Estado un motivo suficiente para cambiar el rumbo de la Política Económica prevaleciente. En comparación con otros países, México ha profundizado las directrices del modelo de economía abierta y agudizado los desequilibrios en distintas esferas de la vida social.

La decisión de priorizar el control de la inflación sobre el crecimiento económico es un factor que explica el pobre desempeño del Producto Interno Bruto (РIв). Durante el periodo 1990-2012 mantuvo una tasa de crecimiento promedio inferior al $2 \%$, que resulta insuficiente para compensar la variación en otras variables vinculadas con el bienestar. La inequidad en su distribución marcó las disparidades regionales y profundizó las desigualdades sociales al interior del país. La región centro concentra el 59.6\% de la riqueza generada entre 1993 y 2012, mientras que la región norte y la sur tienen una participación del 29.89 y $10.95 \%$ respectivamente. Del total de las entidades, nueve concentran el 62\% de la riqueza, pero de estas últimas, tan sólo el Distrito Federal y el Estado de México registran una participación del 32\%. En contraste los estados de Hidalgo, Quintana Roo, Morelos, Aguascalientes, Yucatán, Guerrero, Oaxaca, Durango, Zacatecas, Baja California Sur, Colima, Tlaxcala y Nayarit, de manera conjunta, reportan el 14\%, denotando la desigualdad en la distribución territorial del crecimiento (véase gráfica 1).

El crecimiento demográfico exhibe una distribución similar. De acuerdo con los Censos de Población y Vivienda, entre 1990 y 2010 se presentó un aumento de población: el número de habitantes sumó más de 30 millones, a pesar de una baja en la tasa de natalidad (véase cuadro 2). 
Gráfica 1. México: distribución promedio del PIB por entidad federativa, 1993-2012 (porcentajes)

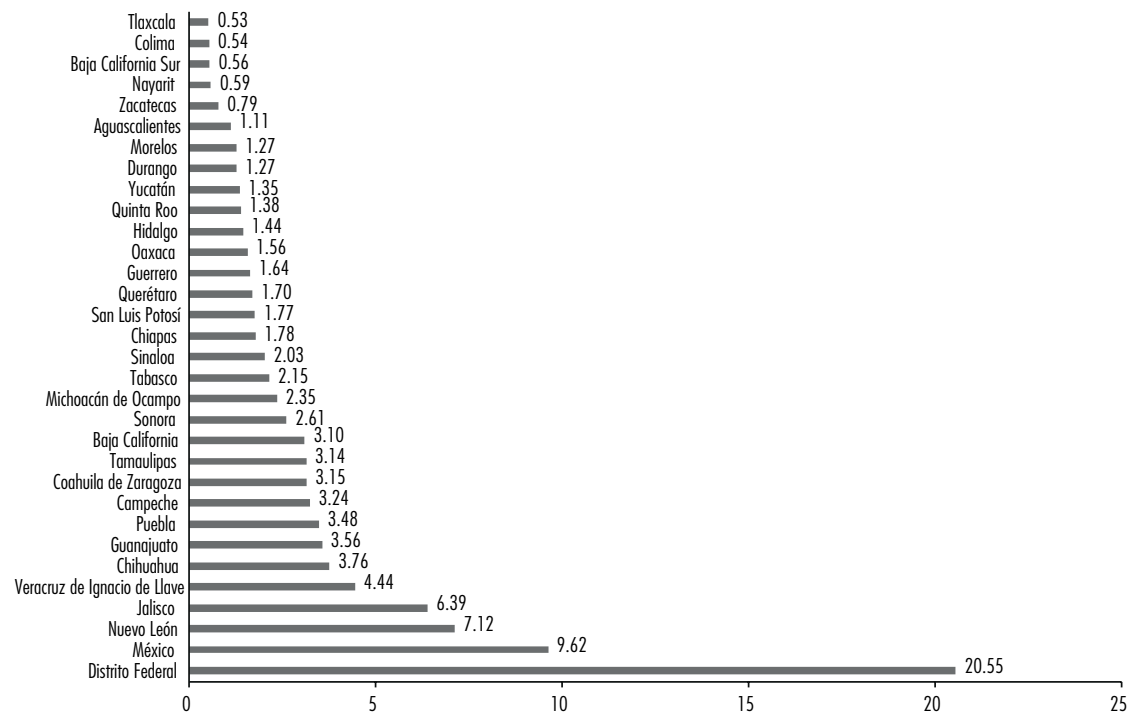

Fuente: INEGI.

Cuadro 2. México: población total, 1990-2010 (número de personas)

\begin{tabular}{lcc}
\hline Año & \multicolumn{2}{c}{ Población } \\
\cline { 2 - 3 } & Absoluto & TCA (\%) \\
\hline 1990 & 81249645 & - \\
1995 & 91158290 & 12.2 \\
2000 & 97483412 & 6.9 \\
2005 & 103263388 & 5.9 \\
2010 & 112336538 & 8.8 \\
\hline Variación $1990 / 2010$ & $38.26 \%$ & \\
\hline
\end{tabular}

Fuente: Censos de Población y Vivienda, varios años; Conteos de Población y Vivienda, varios años, INEGI.

Respecto a su distribución regional, encontramos una clara concentración en el centro del país, con una densidad demográfica del 59.6\%, seguida de la región norte con $26.4 \%$ y, finalmente, la sur con $14.3 \%$. Existe una mayor polarización en la distribución por entidad federativa; el Distrito Federal y el Estado de México albergan una quinta parte de la población con 13.09 y 
8.92\% respectivamente, sin embargo, los estados de Campeche, Colima y Baja California Sur participan sólo con 0.71, 0.55 y 0.46\% respectivamente (véase gráfica 2).

Si bien el crecimiento demográfico ha sido relativamente frenado con políticas de control natal para compensar los efectos de los bajos niveles de crecimiento económico, el costo del ajuste estructural ha recaído sobre los hogares mexicanos, expresándose en una desigual distribución del ingreso, la inalterada composición de la estructura salarial, la pérdida del poder adquisitivo, el aumento del desempleo, el ensanchamiento de la magnitud de la pobreza, pero además, en la reducción del gasto público y del gasto social, que ha provocado un desmantelamiento de los programas de asistencia social y una reducción en las transferencias.

Una evidencia de las repercusiones del desequilibrio entre Política Económica y Política Social es la persistente concentración de la riqueza que desde 1990 no registra cambios la distribución del ingreso. Los datos de la Encuesta Nacional de Ingreso y Gasto de los Hogares (ENIGH) 2012 muestran que actualmente los últimos deciles de ingreso en los hogares (VIII, IX y X), concentran el $62.7 \%$ de los ingresos corrientes totales, mientras que el restante $70 \%$ (deciles I al VII), donde se ubican casi dos terceras partes de la población, absorbieron sólo el $37.3 \%$ (véase cuadro 3). Lo que ha provocado que capas más amplias de población sacrifiquen su consumo para compensar las restricciones del gasto, lo que lleva al deterioro en casi todos los componentes del bienestar, principalmente la alimentación (Torres, 2013: 57-71).

La constitución de la Población Económicamente Activa (PEA) es otro elemento que si bien se ha modificado desde 1995, en términos de composición y estructura salarial, no cuenta con un nivel de vida aceptable debido a que el carácter restrictivo de la Política Económica impide crear empleos suficientes para satisfacer las crecientes demandas del mercado laboral. Esto lleva a la PEA excedente a incorporarse a la economía informal, donde recibe ingresos precarios. Entre 1995 y 2012, los ingresos de la PEA en promedio se ubicaron en un rango de percepciones de entre dos y cinco Salarios Mínimos Mensuales (SMM), a diferencia de los 10 ańos precedentes que osciló entre uno y dos SMM, esta relativa mejoría no refleja mayor bienestar porque más del 70\% de la PEA ocupada no se ubica arriba de esos niveles salariales, lo cual establece límites estructurales en cuanto a posibilidades de reproducción, si lo ubicamos por los costos de acceso a los satisfactores mínimos que no tiene compensación en las transferencias de políticas sociales.

Mientras que en 1995 el 19.10\% de la PEA ocupada se mantuvo bajo rangos de ingreso de un SMM, para el 2012 conformó solo el 13.93\%. Entre la que 
Gráfica 2. México: distribución promedio de la población por entidad federativa, 1990-2012 (porcentajes)

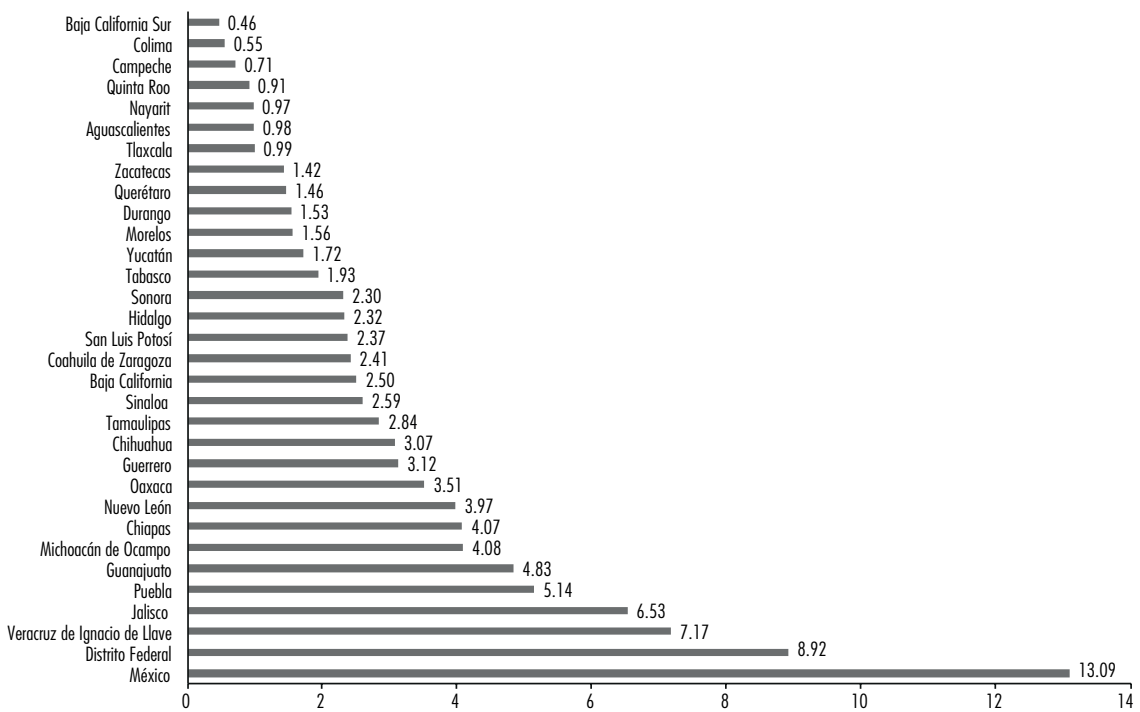

Fuente: elaboración propia a partir de información del Censo de Población y Vivienda, varios años, INEGI.

Cuadro 3. México: distribución del ingreso total por decil de hogares. Años seleccionados (estructura porcentual)

\begin{tabular}{|c|c|c|c|c|c|c|}
\hline \multirow[t]{2}{*}{ Deciles } & \multicolumn{2}{|c|}{1992} & \multicolumn{2}{|c|}{2002} & \multicolumn{2}{|c|}{2012} \\
\hline & $(\%)$ & Acumulado & $(\%)$ & Acumulado & $(\%)$ & Acumulado \\
\hline I & 1.6 & 1.6 & 1.7 & 1.7 & 1.8 & 1.8 \\
\hline$\|$ & 2.8 & 4.4 & 2.9 & 4.6 & 3.1 & 4.9 \\
\hline III & 3.8 & 8.2 & 3.9 & 8.5 & 4.1 & 9.0 \\
\hline IV & 4.8 & 12.9 & 4.9 & 13.5 & 5.1 & 14.1 \\
\hline V & 5.8 & 18.7 & 6.1 & 19.6 & 6.3 & 20.4 \\
\hline VI & 7.2 & 25.9 & 7.4 & 27.0 & 7.6 & 28.0 \\
\hline VII & 9.0 & 34.9 & 9.2 & 36.3 & 9.3 & 37.3 \\
\hline VIII & 11.4 & 46.3 & 11.8 & 48.1 & 11.8 & 49.1 \\
\hline IX & 16.0 & 62.3 & 16.4 & 64.5 & 16.0 & 65.1 \\
\hline$x$ & 37.7 & 100.0 & 35.6 & 100.0 & 34.9 & 100.0 \\
\hline Coeficiente d & & & & & & \\
\hline
\end{tabular}

Fuente: elaboración propia a partir de información de la Encuesta Nacional de Ingreso y Gasto de los Hogares (ENIGH), varios años, INEGI. 
oscilaba entre uno y dos SMm se presenció un descenso al caer de 31 a $23.39 \%$. En contraste, el rango de percepción salarial de dos a tres SMM así como los que se ubican de tres hasta cinco SMM, aumentaron de manera importante (véase cuadro 4).

Cuadro 4. México: distribución de la población económicamente activa (PEA) por nivel de ingresos (estructura porcentual)

\begin{tabular}{lrrrrc}
\hline Nivel de ingresos / Año & 1995 & 2000 & 2005 & 2010 & 2012 \\
\hline Hasta un salario mínimo & 19.10 & 15.40 & 14.50 & 13.00 & 13.93 \\
Más de 1 hasta 2 salarios mínimos & 31.00 & 27.10 & 22.60 & 23.00 & 23.39 \\
Más de 2 hasta 3 salarios mínimos & 14.40 & 18.60 & 19.40 & 21.20 & 21.79 \\
Más de 3 hasta 5 salarios mínimos & 9.50 & 14.90 & 18.20 & 17.10 & 15.05 \\
Más de 5 salarios mínimos & 7.10 & 11.10 & 10.40 & 8.80 & 7.89 \\
No recibe ingresos & 15.30 & 10.00 & 9.70 & 8.40 & 8.29 \\
No especificado & 3.70 & 2.90 & 5.30 & 8.50 & 9.66 \\
\hline Totales & 100.00 & 100.00 & 100.00 & 100.00 & 100.00 \\
\hline
\end{tabular}

Fuente: INEGI.

La composición salarial del país también se afectó en términos absolutos y repercute en el incremento de la tasa de desempleo. Esta última ha mantenido una relativa volatilidad. En 1995 registró hasta 6.1\% como consecuencia de la crisis económica desatada a finales de 1994; en años posteriores osciló por debajo del $4 \%$, pero a partir de 2008, por influencia de la crisis económica mundial la intensificación de las políticas de libre mercado, repuntó por arriba del $4.5 \%$ (véase gráfica 3 ).

Otro factor explicativo de los límites de la composición salarial para mejorar el nivel de bienestar de los hogares mexicanos radica en la pérdida del poder adquisitivo, consecuencia de la contención y el ajuste del salario para alcanzar los objetivos de la estrategia macroeconómica vigente. La contención salarial por debajo de los incrementos inflacionarios constituye la causa estructural que explica la pérdida del poder de compra y de las restricciones al gasto de los hogares que ha disminuido 42\% en términos reales entre 1990 y 2012 e implica un comportamiento paralelo al incremento de los niveles de pobreza y pobreza extrema (véase gráfica 4). 
Gráfica 3. México: tasa de desempleo, 1990-2013

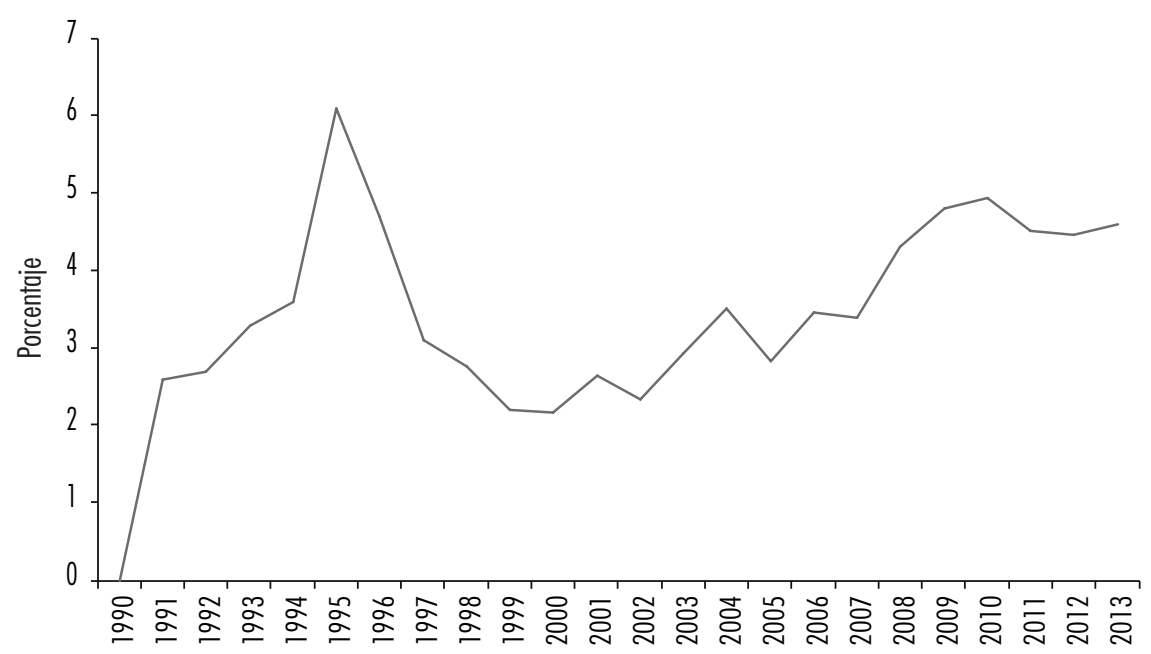

Fuente: INEGI.

Gráfica 4. México: evolución del poder adquisitivo, 1990-2013

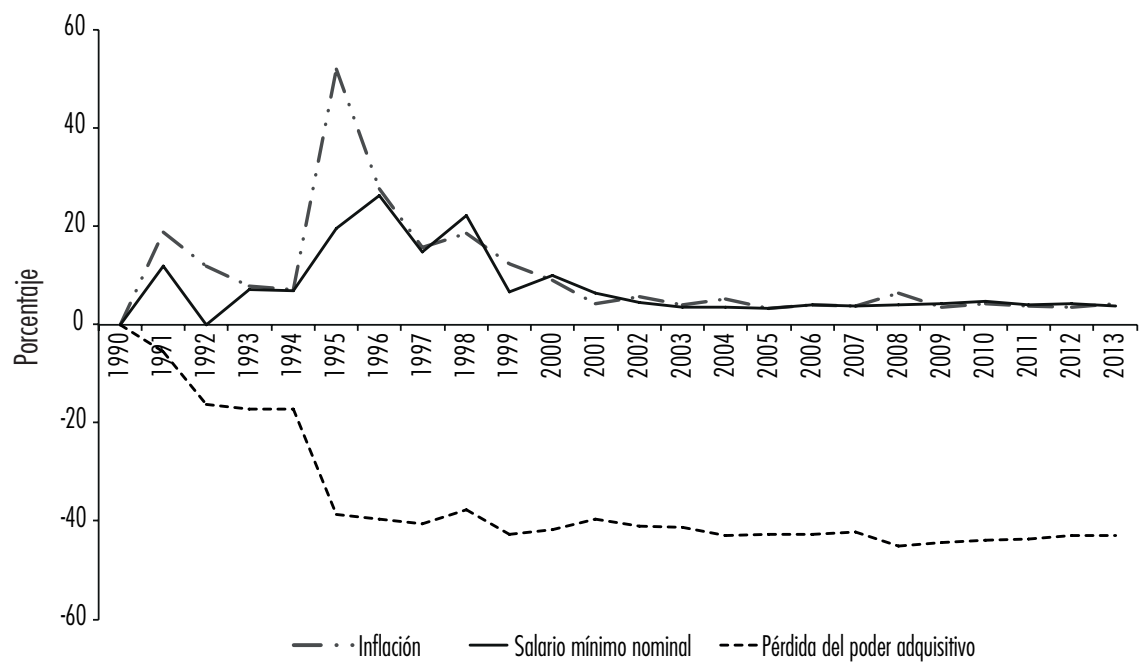

Fuente: elaboración propia a partir de información de la Comisión Nacional de Salarios Mínimos (Conasami) y del INEGl. 
Según datos del Consejo Nacional de Evaluación de la Política Social (Coneval), entre 1992 y 2012 el número de personas en condiciones de pobreza, medidas a través del ingreso, aumentó significativamente: la pobreza alimentaria creció el $24.27 \%$, la de capacidades un $27.59 \%$ y finalmente, la de patrimonio se incrementó en un $37.97 \%$. Sin embargo, uno de los saldos más desfavorables de la actual Política Económica es que 19.70\% de la población nacional no cuenta con los recursos suficientes para acceder a una Canasta Básica Alimentaria (СвA), lo que provoca desequilibrios multidimensionales y representa ya un factor claro de la desigualdad económica (véase cuadro 5).

Si bien el Estado mexicano, en su intento por resolver los desequilibrios internos generados por las asimetrías en el desarrollo económico y por la actual forma de conducir la Política Económica, ha implementado mecanismos orientados a la reasignación del ingreso mediante el gasto social, estos no podrán ser suficientes dados los desequilibrios estructurales presentes entre un crecimiento lento y el incremento de las dimensiones de la problemática social.

La posibilidad de respuesta de la Política Social se ha visto mermada por la reducción del gasto público y del gasto social, pero sobre todo por el papel marginal que tiene dentro de la agenda del desarrollo nacional. Si bien durante los años noventa el rubro presentaba crecimientos anuales por encima del $20 \%$, al inicio del presente siglo no ha reportado aumentos mayores al $15 \%$. En 2010 y 2011 apenas se lograron incrementos del 10\%, y en los dos últimos años no han rebasado el $7.5 \%$ (véase gráfica 5 ).

Lo anterior es reflejo de las limitantes que la actual Política Económica ha impuesto a la Política Social y la incapacidad de esta última para compensar las afectaciones sociales. Resultado de ello es la reducción en la provisión de bienes y servicios públicos, que han sido reorientados con transferencias indirectas y paulatinas hacia el sector privado, el cual oferta ahora los principales rubros de bienestar. Esto responde a la mayor demanda generada por el aumento demográfico, pero se limita a estratos reducidos de población que de por sí cuentan con recursos adicionales para su acceso. 
Cuadro 5. México: evolución de la pobreza por la dimensión del ingreso, 1992-2012 (porcentaje)

\begin{tabular}{lccc}
\hline Año & \multicolumn{3}{c}{ Nacional $^{*}$} \\
\cline { 2 - 4 } & Alimentaria & Capacidades $^{*}$ & Patrimonio \\
\hline 1992 & 21.40 & 29.70 & 53.10 \\
1994 & 21.20 & 30.00 & 52.40 \\
1996 & 37.40 & 46.90 & 69.00 \\
1998 & 33.30 & 41.70 & 63.70 \\
2000 & 24.10 & 31.80 & 53.60 \\
2002 & 20.00 & 26.90 & 50.00 \\
2004 & 17.40 & 24.70 & 47.20 \\
2005 & 18.20 & 24.70 & 47.00 \\
2006 & 14.00 & 20.90 & 42.90 \\
2008 & 18.60 & 25.50 & 47.80 \\
2010 & 18.80 & 26.60 & 51.10 \\
2012 & 19.70 & 28.00 & 52.30 \\
\hline Promedio & 22.01 & 29.78 & 52.51 \\
\hline
\end{tabular}

"El Coneval define la pobreza alimentaria como la incapacidad para obtener una Canasta Básica Alimentaria, aun usando todo el ingreso disponible en el hogar. La pobreza de capacidades representa la insuficiencia de ingreso disponible para adquirir el valor de la canasta alimentaria y efectuar los gastos necesarios en salud y en educación, aun dedicando el ingreso total de los hogares sólo para estos fines. La pobreza de patrimonio atañe a la insuficiencia del ingreso disponible para adquirir la canasta alimentaria, así como para realizar los gastos necesarios en salud, vestido, vivienda, transporte y educación, aunque la totalidad del ingreso del hogar sea utilizado para la adquisición de estos bienes y servicios.

Fuente: estimaciones de Coneval con base en las Encuestas de Ingreso y Gasto de los Hogares (ENIGH) de 1992 a 2012. 
Gráfica 5. México: evolución del gasto público y gasto social, 1990-2013

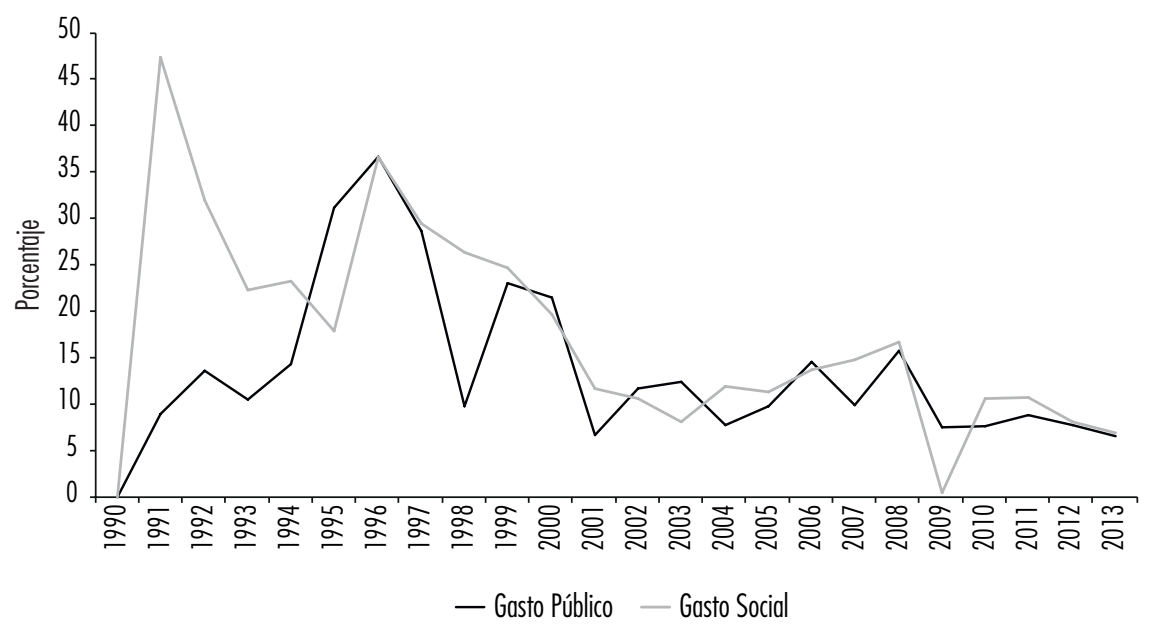

Fuente: elaboración propia a partir del Sexto Informe de Gobierno, Felipe Calderón Hinojosa. Segundo Informe de Gobierno, Enrique Peña Nieto.

\section{CONCLUSIONES}

La apertura comercial y las reformas estructurales han marcado un parte aguas en el rumbo de la economía nacional a partir de la reducción de las funciones del Estado nacional impuesta por las políticas de corte neoliberal. Los efectos directos son la reorientación acotada de la Política Económica que llevaron a una focalización de la Política Social ante la reducción del gasto público. Con ello, el Estado Nacional abandonó la función de promotor del desarrollo que mantuvo durante la vigencia del modelo de industrialización por sustitución de importaciones. Las directrices del modelo de economía abierta, aplicados en la conducción de la Política Económica, han reducido las posibilidades de cobertura de la atención social, obligado a maximizar los recursos y también a restringir los beneficios que puede traer una distribución equitativa de la riqueza.

Si bien se buscó paliar los efectos derivados de la crisis de la deuda a través de un plan de estabilización, la evidencia empírica muestra que la economía, por el contrario, se ha desestabilizado; el crecimiento económico paralizado y los costos de dicha desestabilización han recaído esencialmente sobre los hogares, aumentando las cifras de población en condiciones de pobreza. La concentración del ingreso, la tasa de desempleo, los desequilibrios macro- 
económicos y las crisis recurrentes, junto con el aumento de la pobreza y la desigualdad social, denotan la necesidad de reorientar el proyecto de desarrollo nacional hacia una distribución más justa que lleven a mejorar sustancialmente las condiciones de bienestar.

La influencia de los lineamientos de la actual Política Económica de orden global, no sólo ha mostrado su incapacidad para crear condiciones de bienestar, sino además, ha neutralizado los efectos de la Política Social, la cual hoy en día se limita a tratar de contener el descontento social de la población marginada del país, aunque la violencia social se incrementó a niveles sin precedentes y tiene sus orígenes en la implementación de un modelo económico concentrador. Prueba de ello es que si bien han aumentado los recursos para el combate a la pobreza y desigualdad social, paradójicamente, su nivel y magnitud también se ha incrementado. De esta manera, la realidad histórica demanda una transformación inmediata tanto de la Política Económica como de la Política Social, de lo contrario los costos sociales seguirán incrementándose y cobrarán su factura vulnerando la propia seguridad nacional.

\section{BIBLIOGRAFÍA}

Arellano, Juan Pablo (1985), "Política social y pobreza en el régimen neoliberal", en Rolando Franco y Carmen Barros (comp.), Aspectos metodológicos de las políticas de desarrollo social, Estudios ILPES UNiCef Sobre Políticas Sociales, Santiago de Chile, pp. 41-45.

Barba Solano, Carlos (2004), Politicas sociales. Régimen de bienestar y reforma social en México, Cepal, División de Desarrollo Social, Santiago de Chile, julio.

Boltvinik, Julio (2005), Ampliar la mirada. Un nuevo enfoque sobre la pobreza y el florecimiento humano, Tesis Doctoral, CIESAs, abril, Guadalajara, México. Boltvinik, Julio y Alejandro Marín (2003), "La canasta normativa de satisfactores esenciales de la Coplamar. Génesis y desarrollos recientes", en Comercio Exterior, vol. 53, núm. 5, México, pp. 473-484.

Campos Ríos, Guillermo (2010), "Política social y empleo en México", en Ignacio Llamas Huitron, Nora Garro Bordonario y Guillermo Campos Ríos (coords.), Política Social: enfoques y análisis, Universidad Autónoma Metropolitana Unidad Iztapalapa, México, pp. 47-69.

Cruz, Moritz y Mayrén Polanco (2014), "El sector primario y el estancamiento económico en México", en Revista Problemas del Desarrollo, vol. 45, núm. 178, IIEC - unaM, México, pp. 9-33. 
Cardozo, Brum Myriam Irma (2005), "Neoliberalismo y eficiencia de los programas sociales en México", en Política y Cultura, núm. 24, México, pp. 169-186.

Chossudovsky, Michel (2003), Globalización de la pobreza y nuevo orden mundial, Siglo XXI Editores-CIICH-UnAm, México.

Damián, Araceli (2002), Cargando el ajuste: los pobres y el mercado de trabajo en México, El Colegio de México, México.

Esping-Andersen, Gosta (1999), The Three Worlds of Welfare Capitalism, Cambridge University Press, United Kingdom.

Franco, Rolando (1985), "Significados y contenidos del desarrollo social y de las políticas sociales", en Rolando Franco y Carmen Barros (comps.), Aspectos metodológicos de las politicas de desarrollo social, Estudios ILPES unicef Sobre Políticas Sociales, Santiago de Chile, pp. 13-23.

Flinn, Michael W. (1970), Orígenes de la Revolución Industrial, Instituto de Estudios Políticos, Madrid, España.

Girón, Alicia (1991), Cincuenta años de deuda externa, Instituto de Investigaciones Económicas, IIEC-UnAM, México, pp. 50-112.

(2004), "Deuda externa en los países emergentes”, en Eugenia Correa y Alicia Girón (coords.), Economia Financiera Contemporánea. Las ciencias Sociales, tomo I, Miguel Ángel Porrúa, México, pp. 189-208.

(2006), "Financiamiento del desarrollo. Endeudamiento externo y reformas financieras", en Gregorio Vidal y Arturo Guillén R. (comps.), Repensar la teoría del desarrollo en un contexto de globalización. Homenaje a Celso Furtado, Edición y Distribución Cooperativa, Consejo Latinoamericano de Ciencias Sociales (Clacso), Buenos Aires, Argentina, pp. 125-142.

Gordon, David (2009), “Justicia social y política pública. La búsqueda de la equidad en diversas sociedades", en Revista Mundo Siglo XXI, vol. v, núm. 17, CieCAS-IPN, México, pp. 15-27.

Gordon, Sara (2001), "Ciudadanía y derechos sociales: ¿criterios distributivos?” en Alicia Ziccardi (comp.), Pobreza, desigualdad social y ciudadania. Los limites de las politicas sociales en América Latina, CLACso, Buenos Aires, Argentina, pp. 23-36.

Guillén Romo, Arturo (2001), México hacia el siglo XXI. Crisis y modelo económico alternativo, UAM-Plaza y Valdés, México.

Guillén Romo, Héctor (1997), La contrarrevolución neoliberal en México, Era, México.

Hobsbawm, Eric J. (1983), "La crisis del siglo Xviı", en Trevon Aston (comp.), Crisis en Europa, 1560-1660, Alianza, Madrid, pp. 15-71. 
Jusidman, Clara (2009), "Desigualdad y política social en México”, en Nueva Sociedad, núm. 220, Buenos Aires, pp. 190-206.

Montagut, Teresa (2008), Política Social. Una introducción, Ariel, España.

Pérez, Carlota (1996), "La modernización industrial en América Latina y la herencia de la sustitución de importaciones", en Comercio Exterior, vol. 46, núm. 5, mayo, México, pp. 347-363.

Rheinheimer, Martin (2009), Pobres, mendigos y vagabundos: la supervivencia en la necesidad, 1450-1850, Siglo XXI Editores, Madrid, España.

Sotelo Valencia, Adrián (2010), Crisis capitalista y desmedida del valor. Un enfoque desde los Grundrisse, Ítaca, México.

Torres Torres, Felipe (2003), "La visión teórica de la seguridad alimentaria como componente de la seguridad nacional", en Felipe Torres Torres (coord.), Yolanda Trápaga Delfín et al. (coautores), Seguridad alimentaria: seguridad nacional, IIEC-UNAM / ENTS / Plaza y Valdés, México, pp. 15-52. (2013), "El acceso a la alimentación como factor de desigualdad", en Leticia Cano Soriano (coord.), Pobreza y desigualdad social. Retos para una reconfiguración de la Politica Social, unam-EnTs, México, pp. 57-71.

Townsend, Peter (2003), "La conceptualización de la pobreza", en Comercio Exterior, vol. 53, núm. 5, mayo, México.

Thompson, E. P. (2002), "La economía moral de la multitud en la Inglaterra del siglo xvirı", en Obra esencial, Crítica, Barcelona.

Uribe Gómez, Mónica (2011), "Enfoques contemporáneos de la política social en México", en Espiral, vol. xviıI, núm. 52, septiembre-diciembre, Universidad de Guadalajara, México, pp. 37-75.

Vidal Villa, José María (1998), Mundialización. Diez tesis y otros artículos, Icaria, Barcelona.

Villarespe Reyes, Verónica (2002), Pobreza: teoría e historia, IIEC-UnAM-Casa Juan Pablos, México. 
